\title{
Time-Domain Correlation Quantitative Analysis Method of Regional Rainfall-Landslide Displacement Responses Based on a Time-Domain Correlation Model
}

\section{Tingchen Wu}

Faculty of Geomatics Lanzhou Jiaotong University

Xiao Xie ( $\nabla$ xiexiao@iae.ac.cn)

Zhejiang Hi-Target Spatial Information Technology Co.,Ltd https://orcid.org/0000-0002-2598-0047

\section{Qing Zhu}

Faculty of Geosciences and Environmental Engineering Southwest Jiaotong University

\section{YeTing Zhang}

Wuhan University State Key Laboratory of Information Engineering in Surveying Mapping and Remote Sensing

\section{Haoyu Wu}

Faculty of Geosciences and Environmental Engineering,Southwest Jiaotong University

\section{Haowei Zeng}

Faculty of Geosciences and Environmental Engineering,Southwest Jiaotong University

\section{Manuscript}

Keywords: Regional Rainfall, Landslide Displacement, Time-domain Correlation Modeling, Quantitative Response Analysis, Impulse Response Function, Signal Correlation

Posted Date: February 4th, 2021

DOl: https://doi.org/10.21203/rs.3.rs-165789/v1

License: (c) (i) This work is licensed under a Creative Commons Attribution 4.0 International License. Read Full License 
*Ethical Statements

2 Ethical Statement for Natural Hazards

31 testify on behalf of all co-authors that our article submitted to Natural Hazards:

4 Title: Time-domain correlation quantitative analysis method of regional rainfall-landslide

5 displacement responses based on a time-domain correlation model

6 All authors: Tingchen Wu; Xiao Xie; Qing Zhu; Yeting Zhang; Haoyu Wu; Haowei Zeng

7 1) This material has not been published in whole or in part elsewhere;

8 2) The manuscript is not currently being considered for publication in another journal;

9 3) All authors have been personally and actively involved in substantive work leading to the 10 manuscript, and will hold themselves jointly and individually responsible for its content.

\section{Authors}

12 Tingchen Wu [First Author]

13 Faculty of Geomatics, Lanzhou Jiaotong University, Lanzhou 730070, China

14 Faculty of Geosciences and Environmental Engineering, Southwest Jiaotong University, Chengdu 15 611756, China

16 Email: giswtchen@163.com

17 ORCID: 0000-0002-0777-3247

18 Xiao Xie [Corresponding Author]

19 R\&D Department, Zhejiang Hi-Target Spatial Information Technology Co., Ltd., Huzhou 313200, China

20 Sichuan Visual Smart Map Spatial Information Technology Co., Ltd., Chengdu 610036, China

21 Email: xiexiao@iae.ac.cn

22 ORCID: 0000-0002-2598-0047

23 Qing Zhu

24 Faculty of Geosciences and Environmental Engineering, Southwest Jiaotong University, Chengdu 25 611756, China

26 Sichuan Visual Smart Map Spatial Information Technology Co., Ltd., Chengdu 610036, China

27 Email: zhuq66@263.net

28 Yeting Zhang

Wuhan University State Key Laboratory of Information Engineering in Surveying, Mapping and Remote Sensing, Wuhan 430079, China;

31 Email: zhangyeting@whu.edu.cn

32 Haoyu $\mathrm{Wu}$

33 Faculty of Geosciences and Environmental Engineering, Southwest Jiaotong University, Chengdu 34 611756, China

35 Email: haoyu.wu@my.swjtu.edu.cn

36 Haowei Zeng

37 Faculty of Geosciences and Environmental Engineering, Southwest Jiaotong University, Chengdu 38 611756, China

39 Email: zenghaowei@my.swjtu.edu.cn

40 Time-domain correlation quantitative analysis method of regional 
Abstract Landslide deformation is the most intuitive and effective characterization of the evolution of landslides and reveals their inherent risk. Considering the inadequacy of existing deformation monitoring data in the early warning of landslide hazards, resulting in insufficient disaster response times, this paper proposes a time-domain correlation model. Based on a regional rainfall-landslide deformation response analysis method, a time-domain correlation measure between regional rainfall and landslide deformation and a calculation method based on impulse response functions are proposed for prevalent rainfallinduced landslide areas, and the correlation with the rainfall-triggered landslide deformation mechanism is quantitatively modeled. Furthermore, using rainfall monitoring data to optimize the indicator system for landslide deformation monitoring and early warning significantly improves the preliminary warning based on landslide deformation. The feasibility of the method proposed in this paper is verified by analyzing the historical monitoring data of rainfall and landslide deformation at 15 typical locations in 5 landslide hidden hazard areas in Fengjie County, Chongqing city. (1) The correlation models for the XP landslide and XSP landslide involve a 5-day lagged correlation under a 56-day cycle and a 18-21-day lagged correlation under a 49-52-day cycle, which means that the deformation in the above areas can be modeled cyclically according to monitoring data, and early landslide warnings can be provided in advance with a lag time. (2) The correlation models for the TMS landslide and OT landslide show consistent correlations under a 48-50-day cycle and a 58-day cycle, which means that the deformation in the above areas can be predicted based on rainfall accumulation, and real-time warnings of future landslide deformation and displacement can be obtained. (3) The HJWC landslide presents a disorderly correlation pattern, which means that a preliminary landslide deformation warning cannot be provided based on rainfall alone; other monitoring data need to be supplemented and analyzed.

Keywords: Regional Rainfall; Landslide Displacement; Time-domain Correlation Modeling; Quantitative Response Analysis; Impulse Response Function; Signal Correlation

Foundation: The National Key Research and Development Program of China (No. 2018YFB0505404) Introduction

Regional rainfall-triggered landslides, which are characterized by large masses, instantaneous sliding, and violent and large extents of damage, are one of the main types of geological disasters in China(Yuan 2005, Yue-li et al. 2016, Ze-lin et al. 2020). Statistically, most of the main landslides that have occurred in Southwest China over the past 40 years were caused by rainfall, which is the main cause of the instability of such landslides(Qiu-xiang et al. 2020). Hence, landslide deformation monitoring data provide important information for the early warning of various landslide risks and for uncovering the key moments of landslide events for their prevention and control(ZHU Qing 2017, Yan et al. 2019, Du et al. 2020). However, because landslides characteristically accumulate deformation slowly and occur instantaneously, it is difficult to achieve a forward-looking landslide risk warning system through only deformation monitoring data; accordingly, the development of additional early warning methods is urgent.

The existing landslide early warning analysis models mainly include dynamic analysis models and logistic regression models. Dynamic analysis models are calculation schemes based on the physical mechanisms of events( $\mathrm{Li}$ and Zhao 2019, Zhiyun et al. 2020); hence, these models are limited to data from the test site or to the research and exploration of a single landslide area and thus cannot meet the requirements for investigating landslide groups in different geological environments(Shu-lin et al. 2020, Tao et al. 2020). In contrast, logistic regression models employ mathematical statistics to perform logistic regression and determine the critical value of landslide rainfall and the probability of landslide occurrence(Yi-ting et al. 2015, ADINEH et al. 2018); however, this method is suitable only for smallscale quantitative research and cannot be used for different categories. 
Rainfall-triggered landslides have been summarized and classified; as a result, the data accuracy requirements are too high, and the calculations are too complicated to meet the warning requirements. In view of these limitations, the combined use of geomechanics, physical mechanics, and numerical analysis models to evaluate the stability of landslides during rainfall events can help predict the development trend of landslides, but the corresponding workload is often large, leading to delays in warnings. As an alternative approach, the monitoring data of landslide deformation characteristics and the rainfall factor, which is the main influence on the landslide process, often have obvious correlations(Ferro et al. 2020, Yin et al. 2016, De-ying et al. 2019). Therefore, it is feasible to predict the risk of landslides by using widely available rainfall monitoring data. Accordingly, establishing an effective correlation model between regional rainfall and landslide deformation monitoring data and thereby achieving quantitative correlations have become key issues for effectively improving the timeliness of landslide early warnings.

In response to the above problems, this paper proposes a time-domain method for the quantitative analysis of the regional rainfall-landslide deformation response. First, according to the seasonal and hysteresis variations of landslide deformation during the infiltration of rainfall into the ground, Using easily accessible regional rainfall and landslide deformation monitoring data, this paper proposes the concept of correlation measures between the two in the time domain to measure the correlation period and signal time shift(Adel et al.); on this basis, the correlation is computed by using the impulse response functions of different characteristics in the signal processing algorithm; Finally, the landslide deformation response to rainfall is quantitatively analyzed. The time-domain correlation model includes a consistency model, a hysteresis model and a disorder model. The proposed method can be applied to historical monitoring data from different areas characterized by hidden landslide hazards; then, the corresponding correlation models can be analyzed and summarized, and the time-domain correlation between the regional rainfall and the deformation of a hidden landslide hazard point can be quantitatively calculated as a reference to predict the future deformation of the landslide affected by rainfall. This method provides a scientific basis for pre-warning systems by effectively extending the time allowed in the early warning of landslides.

\section{Study area}

The experimental area adopted in this paper is within Fengjie County in eastern Chongqing (between $109^{\circ} 1^{\prime} 17^{\prime \prime}$ and $109^{\circ} 45^{\prime} 58^{\prime \prime}$ east longitude and $30^{\circ} 29^{\prime} 19^{\prime \prime}$ and $31^{\circ} 22^{\prime} 23^{\prime \prime}$ north latitude). Fengjie County, located on the eastern edge of the Sichuan Basin (Figure 1), represents the central hinterland of the Three Gorges Reservoir. The study area is in the city of Chongqing and the Yangtze River Three Gorges Project, and the rainfall and environment are closely related(Yin et al. 2016, Tiping et al. 2014). (1)The river flowing through Fengjie County is the Yangtze River, and the county has abundant rainfall with a heavy rainstorm intensity and is characterized by large accumulations of rainfall in a short time and a high erosion intensity. In addition, the distributions of landslides and cumulative rainfall (or strong triggering rainfall) are consistent. The minimum cumulative rainfall for landslides is $200 \mathrm{~mm}$. (2) The geological environment in the study area is relatively fragile. The terrain provides good conditions for surface water infiltration, surface water migration, and the occurrence of landslides(3) The regional landforms are mainly moderately eroded mountain and middle-low mountain landforms and eroded hilly landforms with high hills, large undulations, and steep slopes; developed landslides are also prominent. The sensitive slope is $20^{\circ} \sim 30^{\circ}$, and landslides tend to occur at elevations of $400 \sim 1000 \mathrm{~m}$. This paper selects five rainfall-triggered landslides, including the OT landslide, XP landslide, and HJWC landslide, and a total of 15 representative monitoring points for experiments. Table 1 lists the various monitoring points, which will verify that the method proposed in this paper is suitable with adaptable applicability for 
132
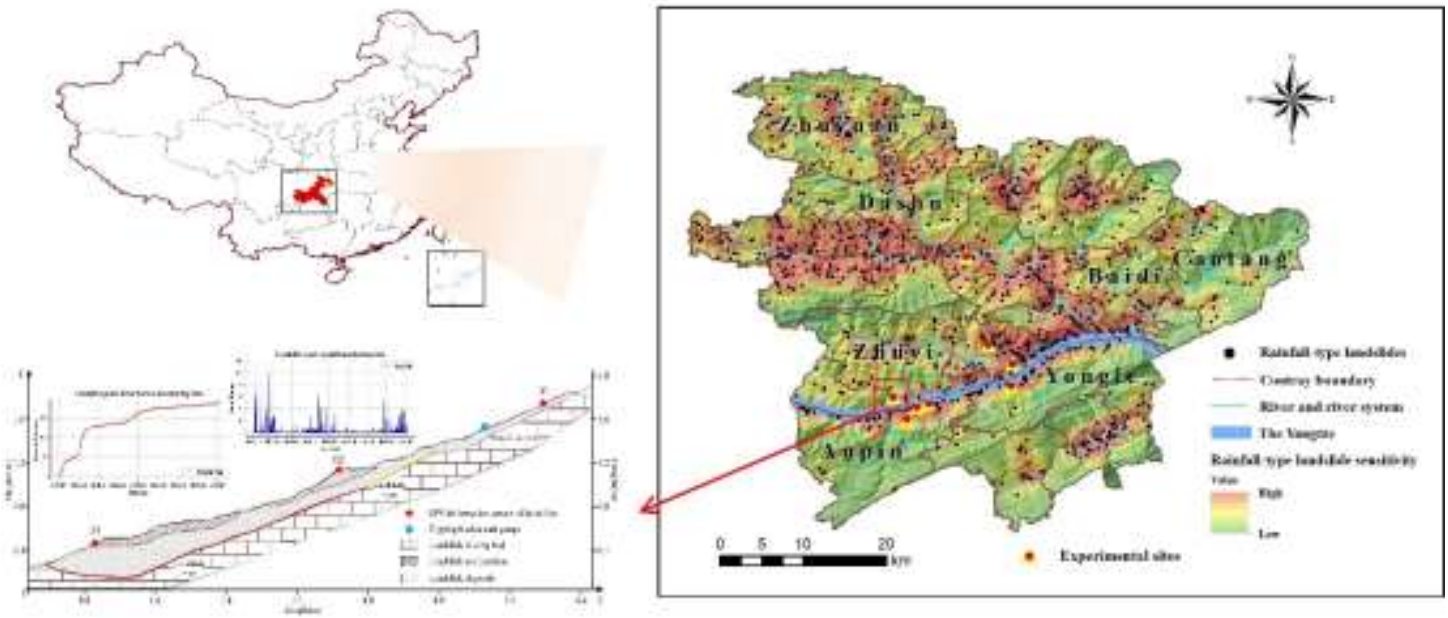

Fig.1 The tests were conducted at rainfall-triggered landslides such as the Xinpu landslide in Fengjie County. Chongqing, China

Table $1 \mathrm{~A}$ qualitative description of the landslide area and monitoring points in the test (partly collected from the literature). Will be used for the quantitative analysis in this paper

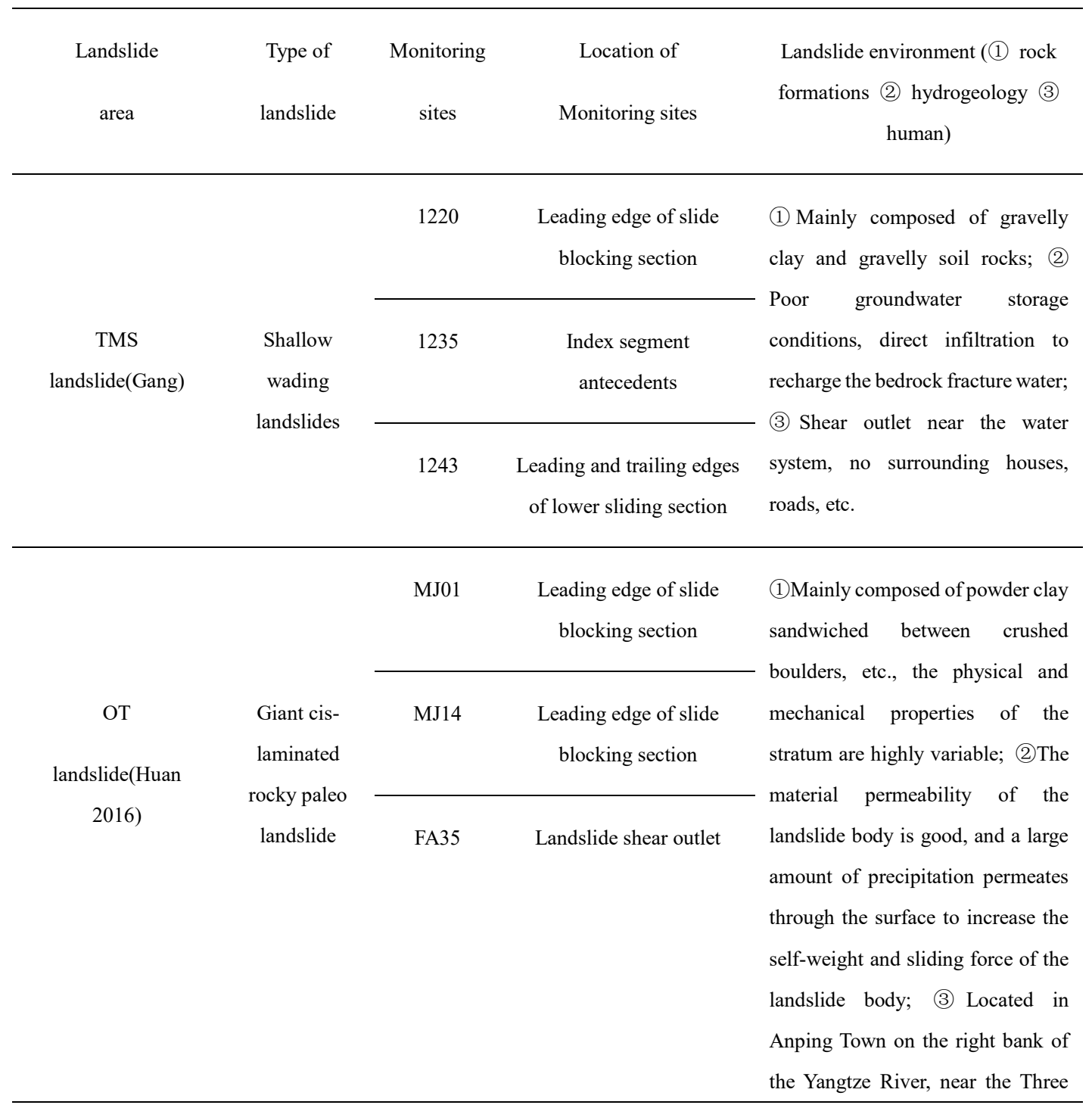




\begin{tabular}{|c|c|c|c|c|}
\hline \multirow{4}{*}{$\begin{array}{l}\text { XP landslide(Shen } \\
\text { 2011) }\end{array}$} & \multirow{4}{*}{$\begin{array}{l}\text { Grade I Very } \\
\text { Large Earth } \\
\text { Slide }\end{array}$} & GDA10068 & $\begin{array}{l}\text { Leading edge of slide } \\
\text { blocking section }\end{array}$ & \multirow{4}{*}{$\begin{array}{l}\text { (1)Moderately weathered - strongly } \\
\text { weathered marl and tuff dominate; } \\
\text { (2) The front edge is continuously } \\
\text { washed by the water of the Yangtze } \\
\text { River and the mechanical properties } \\
\text { of the whole slope are reduced; (3) } \\
\text { The landslide is located on the left } \\
\text { bank of the Yangtze River, near the } \\
\text { densely populated market town of } \\
\text { Anping Township. }\end{array}$} \\
\hline & & GDA10077 & Index segment & \\
\hline & & & antecedents & \\
\hline & & GDA10057 & $\begin{array}{l}\text { Leading and trailing edges } \\
\text { of lower sliding section }\end{array}$ & \\
\hline \multirow{3}{*}{$\begin{array}{l}\text { XSP landslide(Xin } \\
\text { 2016) }\end{array}$} & \multirow{3}{*}{$\begin{array}{l}\text { Thick layer } \\
\text { traction-push } \\
\text { downhill } \\
\text { slides }\end{array}$} & FJ02 & $\begin{array}{l}\text { Leading edge of slide } \\
\text { blocking section }\end{array}$ & \multirow{3}{*}{$\begin{array}{l}\text { (1) The slope is mainly composed of } \\
\text { sandstone chalky clay and gravelly } \\
\text { soil rocks; (2)The sudden cracking } \\
\text { of the back edge of the slope soil } \\
\text { caused by rainfall induced } \\
\text { landslides; (3) There are a few } \\
\text { houses and roads around. }\end{array}$} \\
\hline & & FJ03 & $\begin{array}{l}\text { Index segment } \\
\text { antecedents }\end{array}$ & \\
\hline & & FJ04 & Landslide shear outlet & \\
\hline \multirow{3}{*}{$\begin{array}{c}\text { HJWC } \\
\text { landslide(Yang et al. } \\
\text { 2012) }\end{array}$} & \multirow{3}{*}{$\begin{array}{l}\text { Medium } \\
\text { cascading } \\
\text { bedrock } \\
\text { landslide }\end{array}$} & FJ02 & $\begin{array}{l}\text { Leading edge of slide } \\
\text { blocking section }\end{array}$ & \multirow{3}{*}{$\begin{array}{l}\text { (1) Mainly composed of laminated } \\
\text { mudstone, muddy siltstone and } \\
\text { sandy tuff; (2)Groundwater within } \\
\text { the landslide area is mainly } \\
\text { overburden pore water, influenced } \\
\text { by atmospheric precipitation, with } \\
\text { large seasonal variations; (3) Near } \\
\text { the Three Gorges Reservoir, the } \\
\text { main part of the new site of } \\
\text { Shuanglong Town is located on this } \\
\text { landslide body. }\end{array}$} \\
\hline & & FJ05 & $\begin{array}{l}\text { Index segment } \\
\text { antecedents }\end{array}$ & \\
\hline & & FJ09 & $\begin{array}{l}\text { Leading and trailing edges } \\
\text { of lower sliding section }\end{array}$ & \\
\hline
\end{tabular}

\section{Data and methods}

The experimental data in this paper consist of landslide surface deformation data and regional rainfall data obtained from 2017 to 2020 at the Fengjie regional monitoring point, provided by Chongqing Planning and natural resources Bureau. The deformation variable is the vertical surface displacement monitored by geodetic GPS instruments. The time interval is an hour, and the rainfall is recorded in an hourly increment by a tipping bucket, and the data are unified in time sequences with a unit of days during data preprocessing.

146 Methods 
will greatly affect the movement mechanism of rainfall-induced landslides and the surface deformation of the landslide body. Hence, it is difficult to obtain an accurate correlation between regional rainfall and landslide deformation by conventional statistical analysis. Accordingly, this article proposes the concept of a time-domain correlation measurement to describe the response characteristics of deformation in conjunction with a full understanding of the underlying geological mechanism, and a time-domain correlation model suitable for evaluating various response models is constructed. The principle of this approach is to use landslide deformation monitoring data as the time sequence signal in the usual sense(Chuan et al. 2010), to apply a signal waveform extraction method to identify and quantify the change in the response process, and to introduce an impulse response function to calculate the timedomain correlation measurement and divide the response correlation model(Hunter et al. 1987). This method can provide a universal prior model of landslide deformation for a given rainfall-triggered landslide area.

\section{Time-domain correlation modeling of regional rainfall-landslide deformation monitoring data}

Rainfall-triggered landslides represent sliding deformation phenomena caused by the infiltration of rainfall, and the deformation of a rainfall-induced landslide is generated by different mechanisms(Wang et al. 2020); among them, periodic changes in the surface morphology caused by long-term rainfallinduced surface runoff is particularly important. Rainfall first enters the dry soil, increasing the weight of the sliding body, and when the soil becomes saturated, it affects the stability of the slope; as a result, landslide deformation is lagged (Guangming et al. 2016, Toshiaki et al.). In summary, rainfall and deformation appear to be consistent or hysteresis in time and space. To quantify the correlation characteristics between regional rainfall and landslide deformation, a time-domain correlation measurement is proposed for the above phenomenon, and the following two parameters are estimated to obtain a quantitative description. The conceptual model is illustrated in Figure 2.
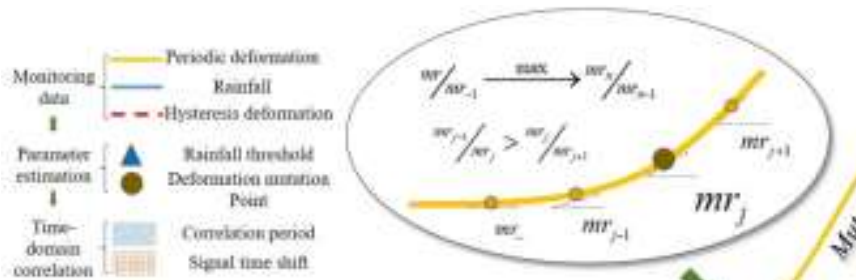

Shable

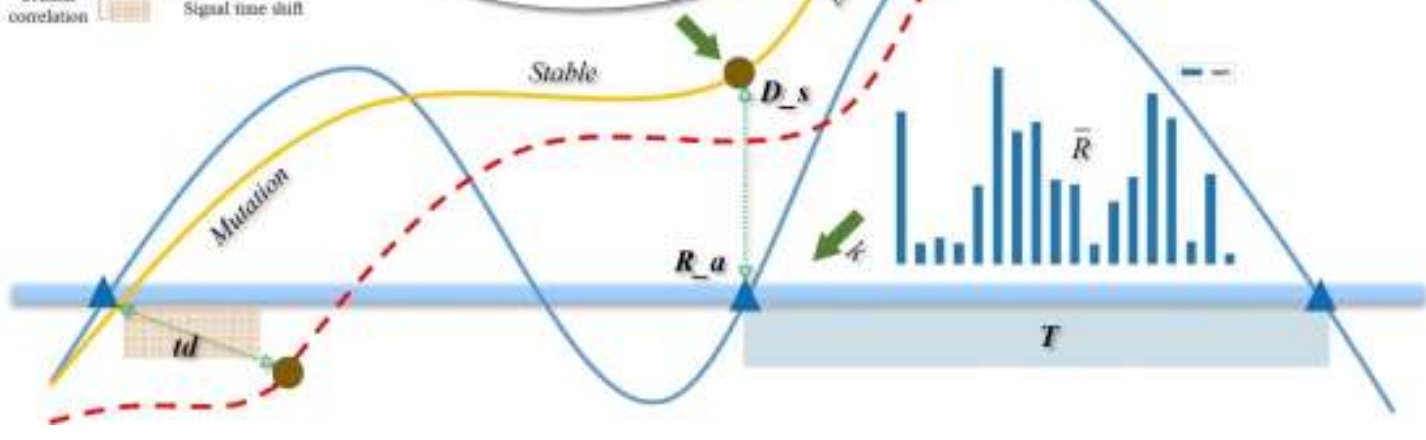

Fig.2 Conceptual diagram of regional rainfall-landslide deformation time-domain correlation measurement

(1) Correlation period $(\mathrm{T})$. Because the occurrence of a landslide requires a certain preliminary accumulation of rainfall and stimulation by a given rain intensity, under a periodic cycle of rainfall, the landslide body is repeatedly subjected to a "push-pull" effect(Li et al. 2019); as a result, the time-domain curve of the landslide displacement signal exhibits a step-like characteristic. Thus, the signal curve in Figure 1 is the combined curve of the rainfall signal and the landslide signal in the time domain. In long time series, the rainfall and landslide signals will have a regular correlation cycle, which represents the consistent correlation between the rainfall in the landslide area and the corresponding cumulative 
deformation. With the correlation time measurement $\mathrm{T}$, the conditions under which a landslide occurs can be quantitatively expressed as the following formula:

$$
T=T_{s}\left(D_{-} s-R_{-} a\right)
$$

(2) Signal time shift (td). Because landslides occur in areas with heterogenous geological conditions, the deformation lags behind the precipitation due to the infiltration of rainfall(Vallet et al. 2016). According to research on the complicated mechanism responsible for level water flow within a landslide body, the nature of this delay behind the rainfall is essentially determined by the time when the water enters the sliding body. The time shift td in Figure 1 is used as a time-domain measure to quantitatively summarize the response (namely, the correlation period T) of landslide deformation to rainfall events and is quantitatively expressed as the following formula:

$t d=t_{s}\left(D_{-} s-R_{-} a\right)$

The product between the correlation period $\mathrm{T}$ and the sampling duration $\mathrm{t} \_\mathrm{s}$, that is, the time shift $\mathrm{td}$ of the lagged signal, can be correlated with the estimated future deformation of the landslide with the realtime rainfall ahead of a lag time.

The abovementioned critical value $\mathrm{R} \_$a of rainfall-triggered deformation is extracted by quantitatively partitioning the regional rainfall history curve to extract the time-domain characteristics of the triggering event at different stages. Formula (3) represents the rainfall interval curve partitioned by determining the average rainfall of each rainfall event. Then, considering the objective environmental factors such as the regional rock composition, surface shape, and soil quality, the effective rainfall coefficient $\mathrm{k}(\mathrm{Chen}$ et al. 2016) is established to calculate R_a as the key parameter of the correlation period T, as shown by $T$ in Figure 2.

$$
\left\{\begin{array}{l}
\bar{R}=\frac{\sum_{i=1}^{n} R_{i} / R \_t_{i}}{n} \\
R \_a=k \bar{R}
\end{array}\right.
$$

The above formula for $\overline{\mathrm{R}}$ signifies the average rainfall in days calculated by counting the $\mathrm{n}$ rainfall events in the area and the number of rainfall days $R_{-} t_{i}$. The effective rainfall coefficient $k$ represents the rainfall retention capacity of the rock and soil and is determined by the regional properties of the rock and soil.

Considering the mutation point $\mathrm{D} \_\mathrm{s}$ of landslide deformation, a large number of landslide examples confirm that landslides, especially gravity-driven landslides, can basically meet the three-stage deformation law proposed by Saito(Saito 1989), namely, initial deformation, followed by constantvelocity deformation and ultimately accelerated deformation. On this basis, the variation in the curve through the deformation analysis is shown in Figure 2. The long time sequence of the landslide deformation response process can be discerned on the basis of whether the signal curve is initially steady before experiencing a sudden increase, reaches its peak, and then becomes stable again. Combined with this principle of signal mutation, the abnormal deformation response point $\mathrm{D}_{-} \mathrm{s}$ is calculated as the key parameter of the signal time shift td, and the corresponding formula is expressed as follows:

When the signal mutation rate $\mathrm{mr}$ is the maximum signal curvature of the overall performance of the landslide in this area, the landslide surface produces abnormal deformation. When the sudden rise in deformation has ceased, a moment will come when the phased maximum of accumulated deformation 
will be generated, after which the landslide evolution process will enter a stable surface deformation stage.

$$
\left\{\begin{array}{l}
m r=\frac{D_{j}-D_{j-1}}{D_{-} t_{j}-D_{-} t_{j-1}} \\
D_{-} s=m r_{-} t\left(m r_{m r_{-1}} \stackrel{\max }{\longrightarrow} m_{n}^{m} / m r_{n-1}\right)
\end{array}\right.
$$

To obtain a credible time-domain correlation measure, it is necessary to extract the signal waveform characteristics of the landslide deformation response process, further calculate the constituent parameters of the correlation measure to obtain the value interval, and introduce the impulse response function during the signal processing phase to calculate the specific measured value, as depicted in Figure 3.
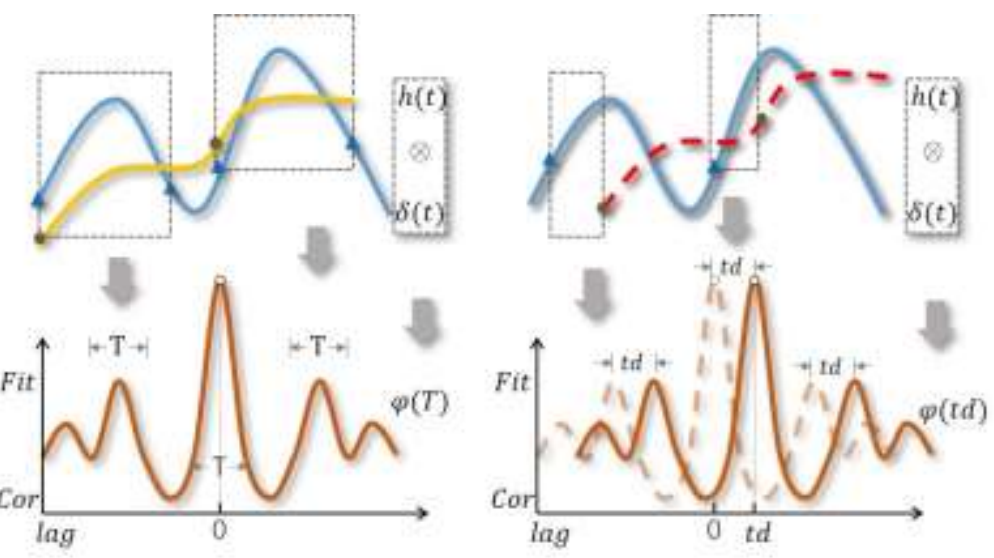

Fig.3 Schematic diagram for calculating time-domain correlation measures based on impulse response functions

However, it is quite difficult to calculate the abovementioned rainfall critical value and landslide mutation point by partitioning the rainfall history curve into multiple processes. At the same time, the monitoring data of a complex sequence cannot be satisfied due to signal noise, a delay in the response and other problems. To accurately fit the correlation measurement of landslides affected by a long-time sequence of rainfall in reality, the impulse response function is introduced during signal processing to calculate the correlation function between the two signal sequences and measure the similarity between the two signals, thereby realizing inversion from geometric distance to the actual time interval(Mucchi et al. 2004, Mbachu 2020). The impulse response function is a cross-correlation function that describes the characteristics of the time-domain system and is widely used in radar, sonar, digital communication and geology(Van 2014). The advantage of the impulse response function is that the algorithm parameters and convolution operation are suitable for signals mixed with additive noise or delayed samples. For a given time sequence, this function can solve for the distance of a real target submerged in noise. In the landslide deformation signal time system continuously affected by regional rainfall, the time series rainfall monitoring signal $\mathrm{R} \_\mathrm{t}$ without random noise is represented by the continuous impulse signal $h(t)$. Similarly, when the input signal is the impulse signal $\delta(t)$ of the landslide deformation fitted waveform, the output response function $\varphi(t)$ of the system is the convolution integral between the input rainfall sequence and the deformation sequence. According to the specific change in the signal under the correlation measurement, the response function is divided into a periodic impulse function and a delay response function.

(1) Impulse period function $\varphi(\mathrm{T})$. In the definition of the relevant time parameters of the response function, the signals $\mathrm{h}(\mathrm{t})$ and $\delta(\mathrm{t})$ are assumed to start at the same time due to the obvious existence of persistent precipitation. When the input rainfall signal shows a periodically repeating waveform, the 
nonlinear subsystem impulse response function is calculated by the periodic input signal with different amplitudes as the response function for measuring the rainfall-landslide deformation correlation period. (2) Delay response function $\varphi(\mathrm{td})$. When the rainfall impulse signal pair and the deformation pulse signal have a relative offset (lag) on the time axis, their related time parameters will also change. This dependence is described by a shift function based on the signal with zero padding while considering the pulse period, as shown in the following formula:

$$
\left\{\begin{array}{l}
\varphi(T)=\int_{-\infty}^{\infty} \delta(T) h(T-\Delta T) d(\Delta T) \\
\varphi(t d)=\int_{-\infty}^{\infty} \delta(T) h(T-t d-\Delta T) d(\Delta(t d+T))
\end{array}\right.
$$

Integrating the abovementioned regional rainfall with the landslide deformation correlation measurement analysis and calculation method, the deformation mechanism and correlation properties of rainfall-triggered landslides can be broadly classified based on the regional monitoring data, as shown in Table 2.

(1) Rainfall-landslide deformation consistency model $\left(\mathrm{M}_{1}\right)$ : Under the action of rainfall and infiltration, the regional surface balance is easily damaged, and sliding occurs. The effect is expressed as a slow and long-term surface deformation process, as a rainfall process, and as a deformation process. There is good temporal consistency between the correlation period $T$ and the pulse period function $\varphi(T)$, and the crosscorrelation and the goodness of fit under the correlation period are the largest. This type of model can determine the real-time landslide deformation and future displacement based on the predicted accumulation of rainfall.

(2) Rainfall-landslide deformation hysteresis model $\left(\mathrm{M}_{2}\right)$ : Affected by factors such as the composition of the geological body, the thickness of the landslide body, etc., rainfall-triggered landslide deformation occurs mostly during the middle and late periods of rainfall or several days later, and the lag times of different types of landslides differ; that is, there is a lag time td and a delay response function $\varphi(\mathrm{td})$. Generally, the lag times of landslides that occur in accumulated soil, landfills, loess, clay, clastics and bedrock range from short to long, and the thickness of the same type of landslide ranges from thin to thickness.

(3) Rainfall-landslide deformation turbulence model $\left(\mathrm{M}_{3}\right)$ : Because landslide deformation is a slope displacement caused by the coupling of multiple factors, some landslide areas may exhibit little rainfall or weak deformation responses to rainfall; that is, there is a discrepancy in the correlation between the landslide response and rainfall. Such situations cannot be accurately forecasted, and early warning systems based on rainfall will fail to predict these landslides.

Table 2 Time-domain correlation model of regional rainfall and landslide deformation

\begin{tabular}{|c|c|c|c|c|}
\hline & $\mathbf{t}$ & $\varphi(t)$ & $\operatorname{Cor}_{\langle\mathbf{t} \mid \mathbf{T}, \mathbf{t d}\rangle}$ & $\mathrm{Fit}_{\langle\mathbf{t} \mid \mathbf{T}, \mathbf{t d}\rangle}$ \\
\hline$M_{1}$ & $\mathrm{~T}$ & $\varphi(\mathrm{T})$ & $\operatorname{Cor}_{\mathrm{T}}>\operatorname{Cor}_{\mathrm{td}}$ & $\mathrm{Fit}_{\mathrm{T}}>\mathrm{Fit}_{\mathrm{td}}$ \\
\hline $\mathbf{M}_{2}$ & $\mathrm{t}$ & $\varphi(\mathrm{td})$ & $\operatorname{Cor}_{\mathrm{td}}>\operatorname{Cor}_{\mathrm{T}}$ & $\mathrm{Fit}_{\mathrm{td}}>\mathrm{Fit}_{\mathrm{T}}$ \\
\hline $\mathbf{M}_{3}$ & $\mathrm{t}$ & l & $\operatorname{Cor}_{t}<0.6$ & $\mathrm{Fit}_{\mathrm{t}}<0.6$ \\
\hline
\end{tabular}



correlation model

This paper uses signal processing technology to quantitatively measure the correlation between regional rainfall and landslide deformation. The flow chart of the method is illustrated in the figure below.

The core steps are as follows: (1)Considering the presence of noise in landslide deformation monitoring data, the proposed method is based on the described time-domain correlation measurement and parameter extraction of the change characteristics of rainfall data and deformation data; this approach adopts an adaptive variable-parameter constrained time-domain classification method for Kalman filtering. (2)Due to the unsynchronized time-domain correlation characteristics between rainfall and deformation in landslide disasters, combined with the abovementioned correlation measure, the correlation between the period and time shift of the monitoring signal transformation structure is realized after noise reduction. (3) An impulse response function that can fuse two or more signal time-domain change characteristics is constructed, and the deformation time series variable is calculated in response to the consistent correlation and goodness of fit of the rainfall variables. (4)The correlation model of the rainfall-landslide deformation response in combination with the above quantitative factors is analyzed, and then the nature of the internal factors is verified; finally, the correlation period between regional rainfall and landslide deformation (the lag time) is quantitatively measured.

\section{(1)Landslide area monitoring data}

\section{(2)Adaptive Kalman filtering for hierarchical noise reduction}

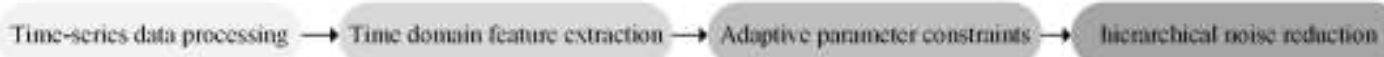

(4)Quantitative analysis of regional rainfall-landslide deformation response

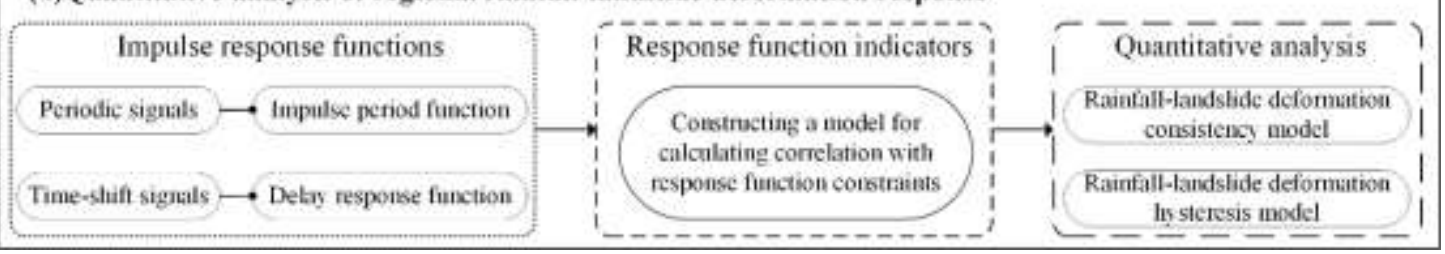

Fig.4 Flow chart of the regional rainfall-landslide deformation quantitative response analysis algorithm

For landslide disasters in different regions, when using monitoring data to analyze, process and predict landslide disasters, there is often a certain error between the observed value and the actual value. How to effectively eliminate this error while retaining the local characteristics is very important in 
analyzing the deformation characteristics of the landslide. In this paper, the Kalman filtering method is used to predict the subsequent time-domain state characteristics through the preliminary time-domain state characteristics and then to combine the observed values to solve for the optimal value, thereby reducing noise while retaining local feature values.

First, the regional rainfall data and landslide deformation monitoring data are processed in a unified time series; that is, the time series quantity $t_{n o r m}$, rainfall $r_{n o r m}$, and deformation variable $d_{n o r m}$ (unit: days) are obtained. For the geological environment, the rainfall coefficient $\mathrm{k}$ is computed, and then the interval threshold and the mutation signal $v_{\text {norm }}$ are calculated according to the rainfall critical value $R_{-} a$ and the mutation point D_s described in formula (3). Finally, the interval is used to perform adaptive Kalman filtering for hierarchical noise reduction on the mutation signal according to the following formula(Wang et al. 2016):

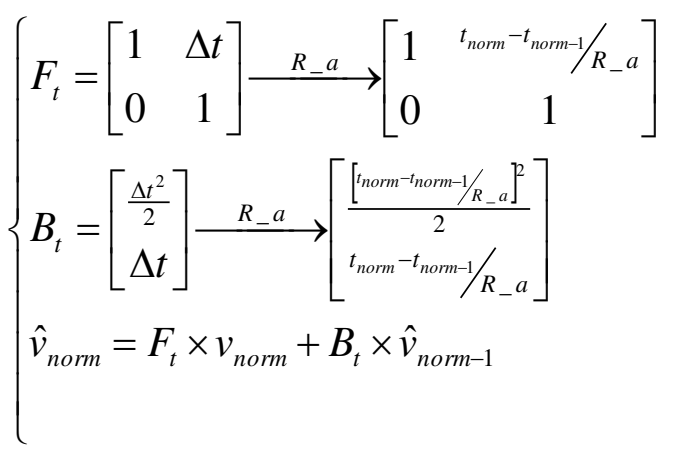

In the above formula, $\mathrm{F}_{-} \mathrm{t}$ and $\mathrm{B} \_\mathrm{t}$ are the state change matrices in the Kalman filter, $\Delta \mathrm{t}$ is the sampling time, $\hat{v}_{\text {norm }}$ is the current estimate, $v_{\text {norm }}$ is the measured value, and $\hat{v}_{\text {norm }-1}$ is the previous estimate.

Because of the seasonal cyclic characteristics of regional rainfall and the asynchronous time-domain correlation between rainfall and deformation in landslide hazards, the combined time-domain waveforms cannot be judged directly, and this paper uses the time-domain correlation measure as a dynamic parameter to transform the monitoring signals into a characteristic structure for the quantitative analysis of regional rainfall-landslide deformation response. Eq. (7) clusters the noise-reduced deformation signals, sudden change signals and rainfall signals based on the correlation period $\mathrm{T}$ (ski and Owczarek 2005). The monitoring signals are divided into several effective time regions by expanding the time series quantity $t_{\text {norm }}$, while the following signal shifts are further applied to the rainfall signals that have been clustered in the time domain according to the time shift quantity td, with the aim of further investigating whether there is a lag between the rainfall and deformation in the region whether there is a lag between rainfall and deformation in the region.

$$
\left\{\begin{array} { l } 
{ f _ { T } : t _ { i } ^ { T } = t _ { 0 } ^ { n o r m } + i \times T } \\
{ d _ { i } ^ { T } = f _ { T } [ \hat { d } ^ { n o r m } ] } \\
{ r _ { i } ^ { T } = f _ { T } [ r ^ { n o r m } ] } \\
{ \hat { v } _ { i } ^ { T } = f _ { T } [ \hat { v } ^ { n o r m } ] }
\end{array} \Rightarrow \left\{\begin{array}{l}
g_{T_{-} t d}: t_{i}^{T-t d}=f_{T}\left[t^{n o r m}-t d\right] \\
d_{i}^{T+t d}=g_{T_{-} t d}\left[\hat{d}^{n o r m}\right] \\
r_{i}^{T_{-} t d}=g_{T_{-} t d}\left[r^{\text {norm }}\right] \\
\hat{v}_{i}^{T+t d}=g_{T_{-} t d}\left[\hat{v}^{n o r m}\right]
\end{array}\right.\right.
$$

To calculate the time-domain correlation measure of regional rainfall-landslide deformation, the following formula combines the signals with the transformed structure to construct a periodic impulse function and a time-delayed impulse function. Based on the correlation model of the response function, formula (8) calculates the correlation Cor and degree of fit (labeled Degree Fit)(Dong et al. 2012), which are used to quantitatively analyze the complex correlation model between landslide deformation and 
rainfall. According to the model judgment table, a consistent correlation model judgment does not need to consider the time-domain shift. The signal is expanded and contracted on the basis of the overall correspondence, the response function index between the two curves is solved with the expanded data, and the correspondence is adjusted simultaneously to reconstruct the signal. As shown in the formula (9), multiple sets of correlations are solved in this manner, and the best set is taken for further analysis. In contrast, the determination of the lag correlation is different from that of the consistent correlation in that the time-domain shift needs to be considered. When the signal is expanded and contracted, the timedomain shift is applied to solve for the correlation, and the degree of fit is compared corresponding to the time-domain response correlation model. The quantitative values of the correlation period $\mathrm{T}$ and signal time shift $\mathrm{td}$ are then calculated backward.

$$
\begin{aligned}
& \left\{\begin{array}{l}
\operatorname{Cor}_{\langle t \mid T, t d\rangle}=\sum_{i=0}^{N-1} \delta_{i}(t) h_{i+t}(t) \\
F_{\langle t \mid T, t d\rangle}=\frac{\sum_{j=0}^{N}\left(\varphi_{i}(t)-\delta_{i}(t)\right)^{2}}{\sum_{j=0}^{N}\left(\varphi_{i}(t)-h_{i}(t)\right)^{2}}
\end{array}\right. \\
& \left\{\begin{array}{l}
\varphi(T)=\int_{-\infty}^{\infty} v_{i}^{T} r_{i}^{T} d(\Delta T) \Rightarrow\left\{\begin{array}{l}
\operatorname{Cor}_{T}=\operatorname{Cor}\left(v_{i}^{T}, r_{i}^{T}\right) \\
\operatorname{Fit}_{T}=\operatorname{Fit}\left(\varphi(T), v_{i}^{T}\right)
\end{array}\right. \\
\varphi(t d)=\int_{-\infty}^{\infty} v_{i}^{T} r_{i}^{T-t d} d(\Delta(t d+T)) \Rightarrow\left\{\begin{array}{l}
\operatorname{Cor}_{t d}=\operatorname{Cor}\left(v_{i}^{T}, r_{i}^{T-t d}\right) \\
\operatorname{Fit}_{t d}=\operatorname{Fit}\left(\varphi(t d), v_{i}^{T}\right)
\end{array}\right.
\end{array}\right.
\end{aligned}
$$

\section{Results}

This paper selects all the GDA10068 monitoring points in the XP landslide area for a quantitative analysis using the proposed time-domain correlation model, as shown in Figure 5, and simultaneously calculates the analysis results at all the monitoring points in the landslide area. First, for the original monitoring data of rainfall and landslide deformation with an hourly sampling interval, the cumulative amount of which is less than one day due to missing data, interpolation is applied to standardize the units to days to obtain continuous deformation cumulative signals and rainfall signals. The parameters D_s and R_a of the time-domain correlation measurement described according to formula 3 and formula 4, respectively, are then calculated, and the rainfall coefficient $\mathrm{k}$ is obtained based on previous research experience in conjunction with the geological environment of the landslide area (Table 1), and the results are shown in Table 3. The gain parameter of the Kalman filter is further updated according to formula (6) to realize adaptive hierarchical noise reduction for the landslide deformation signal. The experimental effect of this filter is shown in Figure 5.

Table. 3 Time domain measurement parameters of monitoring points in landslide area

\begin{tabular}{ccccc}
\hline Monitoring sites & $\boldsymbol{D} \_\boldsymbol{s}$ & $\overline{\boldsymbol{R}}$ & $\boldsymbol{k}$ & \\
\hline 1220 & 1.7628 & & & $\boldsymbol{R}_{-} \boldsymbol{a}$ \\
1235 & 1.3285 & 18.283 & 6.67 & \\
1243 & 0.9477 & & & 149.94 \\
\hline MJ01 & 2.6552 & & 9.74 & \\
MJ14 & 2.9282 & 15.391 & & \\
FA35 & 2.1681 & &
\end{tabular}




\begin{tabular}{llccc}
\hline FJ02 & 2.3611 & & & \\
FJ03 & 2.7911 & 13.764 & 163.65 \\
FJ04 & 1.3659 & & \\
\hline FJ02 & 10.2612 & & 34.17 \\
FJ05 & 9.3689 & 4.404 & 7.76 \\
FJ09 & 10.2251 & & \\
\hline
\end{tabular}

In the signal feature structure transformation stage, the time-domain correlation measures $\mathrm{T}$ and td are used as variable parameters in formula (7), and the ranges are specified here as 0 60 days and 0 30 days, respectively. The example diagram in Figure 5(a) is the feature map of signal clusters at 5, 20, and 40 days. At the same time, a certain clustering parameter is fixed, and td is 1,2 and 3 for the signal time shift. It is obvious that most of the monitoring points in each area record the amount of rainfall, and the deformation signals gradually show the same trend. The correlation degree Cor in formula (8) is used to accurately quantify the accurate value or effective range of the time-domain correlation measure, and the results are shown in Figure 6(b).

In the quantitative analysis of the regional rainfall-landslide deformation response, the correlation function between the rainfall and deformation is constructed according to formula (5) using the rainfalldeformation correlation signal after a series of processing steps. The function performance is shown in example Figure 6(c), and the described impulse response function type corresponds and divides the correlation function of the research point into a pulse period function, a delay response function and a disorder function without changing the properties. Using formula (9), the degree of fit can then be calculated to determine the accurate value or effective range of the time-domain correlation measure. Corresponding to the proposed time-domain correlation model according to the calculated results, there is a delayed response between the rainfall and landslide deformation in the study area, and there is a 5day lag time under a 56-day cycle. In summary, this area can be simulated by a rainfall-landslide deformation hysteresis correlation model.

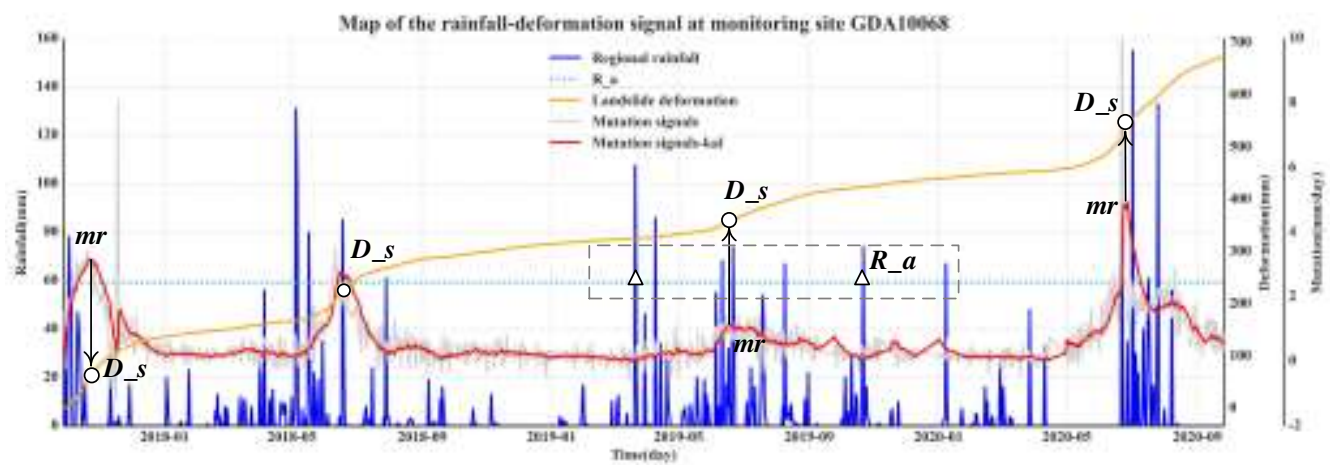

Figure. 5 Map of monitoring data at landslide site GDA10068. Used to calculate rainfall-triggered deformation value, mutation signals and the corresponding Kalman filter results 

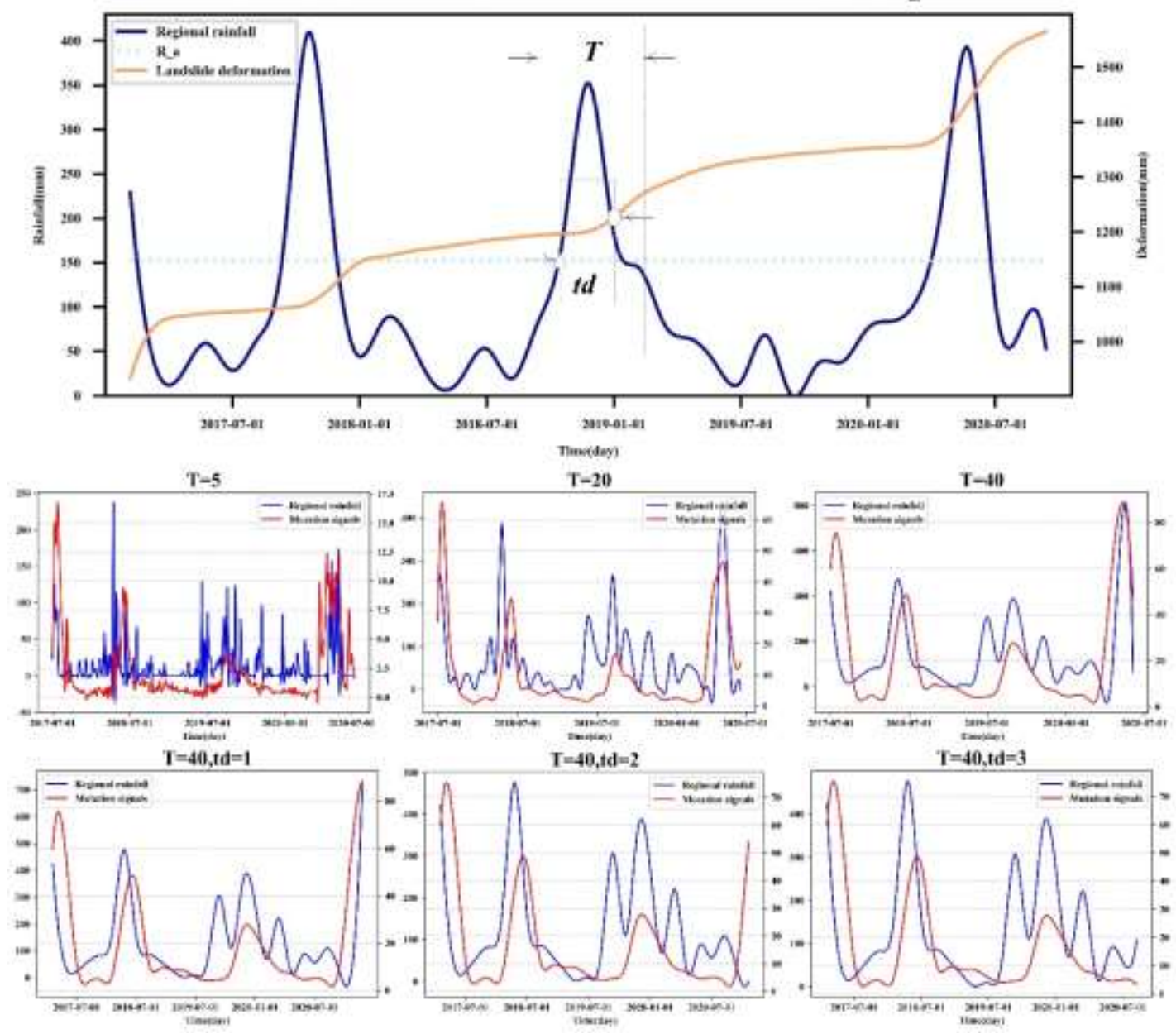

Figure. 6(a) This figure illustrates the process of monitoring signals for period clustering using the time domain correlation measure described and the signal time shifting. The correlation measure Cor is also measured quantitatively

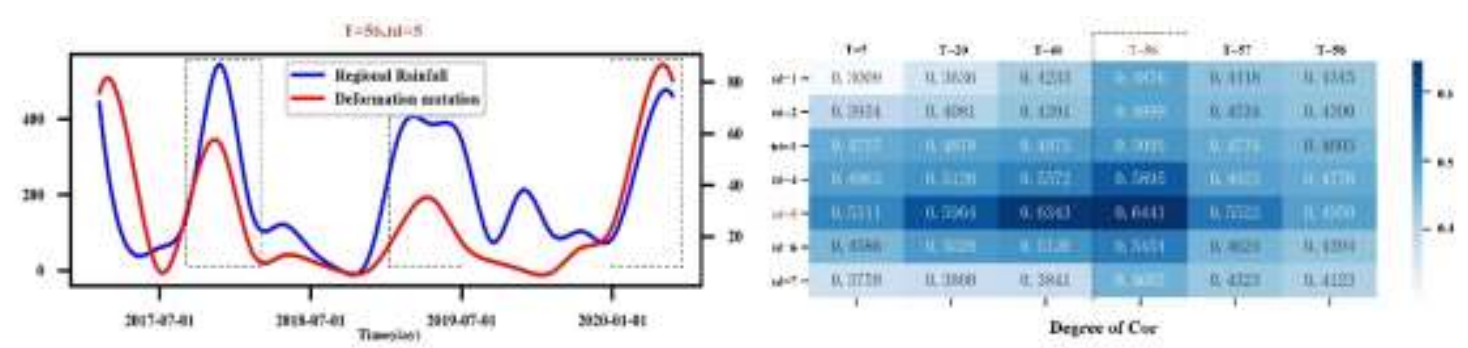

Figure. 6(b) This figure shows the quantitative calculation of the signal after the clustering and time-shifting operations. The value of Cor tells us the optimal T and td
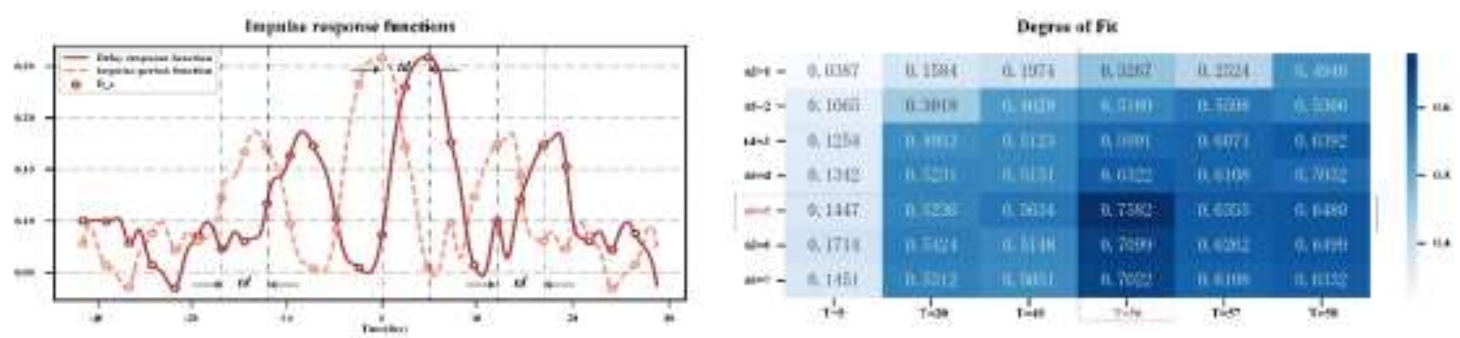
Figure. 6 Map of the results of the test using the time-domain correlation quantitative analysis model at landslide site GDA10068

392 Table. 4 Table of quantitative analysis results of monitoring points in the landslide area

\begin{tabular}{|c|c|c|c|c|c|c|c|c|}
\hline Landslide area & Monitoring sites & $T$ & $t d$ & $\operatorname{Cor}_{T}$ & $\operatorname{Cor}_{t d}$ & $\mathrm{Fit}_{T}$ & $F i t_{t d}$ & $M$ \\
\hline \multirow{3}{*}{ TMS landslide } & 1220 & 48 & 0 & 0.6775 & 0.1162 & 0.7521 & 0.2236 & \\
\hline & 1235 & 48 & 0 & 0.7217 & 0.2158 & 0.7956 & 0.2665 & Rainfall-landslide \\
\hline & 1243 & 50 & 0 & 0.6022 & 0.3547 & 0.7142 & 0.2737 & deformation \\
\hline \multirow{3}{*}{ OT landslide } & MJ01 & 58 & 0 & 0.6931 & 0.2422 & 0.8015 & 0.2483 & consistency model \\
\hline & MJ14 & 58 & 0 & 0.7839 & 0.2216 & 0.8657 & 0.1157 & $M_{1}$ \\
\hline & FA35 & 58 & 0 & 0.6236 & 0.3188 & 0.6934 & 0.2685 & \\
\hline \multirow{3}{*}{ XP landslide } & GDA10068 & 56 & 5 & 0.2574 & 0.6441 & 0.2748 & 0.7582 & \\
\hline & GDA10077 & 56 & 5 & 0.2031 & 0.7105 & 0.1778 & 0.7938 & Rainfall-landslide \\
\hline & GDA10357 & 56 & 5 & 0.1852 & 0.7190 & 0.1862 & 0.8114 & deformation \\
\hline \multirow{3}{*}{ XSP landslide } & FJ02 & 49 & 18 & 0.2276 & 0.7227 & 0.1421 & 0.8624 & hysteresis model \\
\hline & FJ03 & 50 & 21 & 0.2185 & 0.7195 & 0.1488 & 0.8473 & $M_{2}$ \\
\hline & FJ04 & 52 & 20 & 0.2939 & 0.6168 & 0.3162 & 0.7025 & \\
\hline \multirow{3}{*}{ HJWC landslide } & FJ02 & 23 & 0 & 0.1913 & 0.1898 & 0.2483 & 0.2737 & Rainfall landslide \\
\hline & FJ05 & 12 & 6 & 0.3395 & 0.3188 & 0.2926 & 0.1974 & deformation \\
\hline & FJ09 & 10 & 10 & 0.0674 & 0.2483 & 0.1737 & 0.2454 & turbulence model $M_{3}$ \\
\hline
\end{tabular}

\section{Discussion}

Table 4 shows all the proposed index parameters summarized by all the monitoring points through the above calculation process, which can meet the judgment requirements of the time-domain correlation model constructed in this article.

(1) According to the calculation results for the TMS landslide and the OT landslide model, there is a periodic correlation between the rainfall at the monitoring points and the landslide deformation, and the response function constructed by the above signals is expressed as a pulse period function $\varphi(\mathrm{T})$; at the same time period $\mathrm{T}$, the signal correlation and function fitting degree under clustering are both greater than the correlation degree and fitting degree of the time shift td involved in the calculation and correspond to the consistent correlation model; therefore, such areas can be separately measured to determine the historical landslide deformation and displacement based on the amount of rainfall. Periodic accumulations of 48-50 days and 58 days can be used to predict consistent changes in future landslide motion.

(2) According to the model calculation results for the XP landslide and the XSP landslide, there is a periodic correlation between the rainfall at the monitoring points and the landslide deformation, and there is a certain signal time shift, and the response function shows a delayed response function $\varphi(t d)$. The signal correlation degree and function degree involved in the calculation of the time shift td are greater than the correlation degree and the degree of fit under the clustering at period $\mathrm{T}$, which corresponds to the hysteresis correlation model; therefore, there is a certain lag between the rainfall and landslide deformation in the above areas. Periodic changes in duration need to be analyzed in advance by a time shift when predicting future changes to obtain more adequate warning times.

414 (3) The model calculation results between the rainfall and landslide deformation at the HJWC landslide monitoring point all correspond to the turbulent correlation model. Therefore, it is not possible to provide a preliminary warning of landslide deformation based on rainfall alone in this area; rather, the additional analysis of other monitoring information is required. 
Rainfall data are easy to obtain and constitute relatively stable monitoring data, and only surface deformation data are needed to study the significant changes in landslide disasters to achieve effective early warnings(Yue-li et al. 2016, Ze-lin et al. 2020). The method proposed in this paper involves a calculation model for the signal correlation in the time domain. The proposed model can not only quantitatively describe the motion of landslide deformation affected by rainfall but also determine different correlation models based on the rainfall and landslide deformation and calculate the differences between the two under different models. Compared with the existing methods, this time-domain correlation feature also possesses a certain degree of universality and scalability when there is no ultralong time sequence and high-precision monitoring data. In particular, the time-domain correlation model proposed herein is universal and can be used as a general judgment index for all rainfall-triggered landslide disasters; moreover, the complexity of the response calculation method is low. Hence, this model is suitable for supporting the parallel computing of short-term data from multiple monitoring points on large-scale landslides, which is useful for periodic monitoring.

However, for landslide areas with turbulent patterns, it is difficult to obtain regular correlation changes between the regional rainfall and landslide deformation(Zhiyun et al. 2020). Occasionally, large fluctuations in cycles and time shifts occur in the same area. Therefore, further research can focus on strengthening the correlation analysis of monitoring data with a relationship between the reservoir water level and landslide deformation to improve the model indicators of rainfall-triggered landslides and other types of landslides and more accurately establish multifactor constrained time-domain correlation models. Nevertheless, this study provides a scientific and accurate basis for faster and more accurate landslide warnings.

\section{Conclusions}

This paper proposes a method for the quantitative analysis of regional rainfall-landslide deformation responses based on a time-domain correlation model. Considering the problem that the existing methods have difficulty achieving short-term abnormal landslide deformation predictions through environmental rainfall factors, the proposed model is established by using probability statistics and signal processing. Rainfall factors are extracted and analyzed from multimodal landslide monitoring data, and a universal correlation model for different landslide areas is constructed by mining potential and deep correlations between temporal and spatial features. Furthermore, through a quantitative correlation measure, the consistent correlation period and the hysteresis time shift caused by regional rainfall affecting landslide deformation can be obtained, and finally, an effective prediction of landslide deformation can be achieved. Experiments were conducted on rainfall and landslide deformation monitoring data at five landslide locations in Fengjie County, Chongqing(Shen 2011, Yang et al. 2012). The results showed that the rainfall-landslide deformation of the XP landslide and XSP landslide in hidden hazard areas exhibits a delayed correlation. In contrast, the correlation model for the hidden hazard areas of the TMS landslide and OT landslide shows a consistent correlation, verifying the feasibility of this method in studying the deformation of rainfall-triggered landslides. For areas with disorderly correlations, due to the complex causes of landslides, the external hazards affecting their deformation are not equally important, and for some areas, it is difficult to analyze such deep correlations using only rainfall monitoring data. Therefore, different influencing factors such as reservoir water levels should be added.

\section{Reference}

460 ADEL A, ST PHANE L, FRAN OIS N AND BRUNO C Recent Advances in Modeling Landslides 461 and Debris Flows. Springer International Publishing, 2015 p. 
ADINEH F, MOTAMEDVAZIRI B, AHMADI H AND MOEINI A. 2018. Landslide susceptibility mapping using Genetic Algorithm for the Rule Set Production(GARP) model. Journal of Mountain Science 15: 2013-2026.

Egu General Assembly Conference, 2016. p.

CHUAN YE, KUN S AND GANG LH. 2010. Applicability of Time Domain Reflectometry for Yuhuangge Landslide Monitoring. Journal of Earth Science 21: 856-860.

DE-YING L, YI-QING S, KUN-LONG Y, FA-SHENG M, GLADE T AND LEO C. 2019. Displacement characteristics and prediction of Baishuihe landslide in the Three Gorges Reservoir. Journal of Mountain Science 16: 2203-2214.

DONG J, LU ZG, SUN ZH, PENG ZT, XIA YW, SU JQ, FENG J, YUAN HY, HUA L AND TANG J. 2012. Transforming characteristic of phase-shift from frequency-domain to time-domain in frequency-domain holography. Optics \& Laser Technology 44: 594-599.

DU Y, HUANG G, ZHANG Q, GA0 Y AND GA0 Y. 2020. Asynchronous RTK Method for Detecting the Stability of the Reference Station in GNSS Deformation Monitoring. Sensors 20.

FERRO V, CAROLLO FG AND SERI0 MA. 2020. Establishing a threshold for rainfall induced landslides by a kinetic Energy 8 uration relationship. Hydrological Processes.

GANG GF. Analysis of landslide development patterns and hazards in the Wenchuan earthquake. Masters, Chengdu University of Technology.

GUANGMING LI, SHIGUANG XU, WANG Y AND SHUIYUN TU. 2016. Research on the instability mechanism and treatment measures of the filled soil Landslide under heavy rainfall. Journal of China Institute of Water Resources \& Hydropower Research.

HUAN C. 2016. Analysis of Numerical Simulation of Wading Landslide in Three Gorges Reservoir Area Based on Outang Landslide. Mathematical Modelling of Engineering Problems 3.

HUNTER IW, KEARNEY RE AND JONES LA. 1987. Estimation of the conduction velocity of muscle action potentials using phase and impulse response function techniques. Medical \& Biological Engineering \& Computing 25: 121-126.

LI L, YAO X, YAO J, ZHOU Z AND LIU X. 2019. Analysis of deformation characteristics for a reservoir landslide before and after impoundment by multiple D-InSAR observations at Jinshajiang River, China. Natural Hazards 98.

LI X AND ZHAO J. 2019. An overview of particle-based numerical manifold method and its application to dynamic rock fracturing. Journal of Rock Mechanics and Geotechnical Engineering 11: 684-700.

MBACHU CB. 2020. Height Adjustable Sine (HAS) Window Function for Impulse Response Modification of Signal Processing Systems. European Journal of Engineering Research \& Science 5: 367-374.

MUCCHI L, MOROSI S, DEL RE E AND FANTACCI R. 2004. A new algorithm for blind adaptive multiuser detection in frequency selective multipath fading channel. IEEE Transactions on Wireless Communications 3: 235-247.

QIU-XIANG H, XIANG-TAO X, P. H. S. W. KULATILAKE AND FENG L. 2020. Formation mechanism of a rainfall triggered complex landslide in southwest China. Journal of Mountain Science 17: 1128-1148. 
1989. p.

SHEN LS. 2011. Study on the development pattern and instability mechanism of cascading landslides on the reservoir bank in the Three Gorges reservoir area. Masters, Northwest Agriculture and Forestry University.

SHU-LIN R, ZHI-GANG T, MAN-CHAO H, SHI-HUI P, MENG-NAN L AND HA0-TIAN X. 2020. Stability analysis of open-pit gold mine slopes and optimization of mining scheme in Inner Mongolia, China. Journal of Mountain Science 17: 2997-3011.

SKI JM AND OWCZAREK AJ. 2005. A time-domain-constrained fuzzy clustering method and its application to signal analysis. Fuzzy Sets \& Systems 155: 165-190.

TAO W, JIA-MEI L, JU-SONG S, MENG-TAN G AND SHU-REN W. 2020. Probabilistic seismic landslide hazard assessment: a case study in Tianshui, Northwest China. Journal of Mountain Science 17: 173-190.

TIPING D, JIANFEI G, SHIHONG T, GUOYU S, FENG C, CHENGYU W, XURONG L AND DAN H. 2014. Chemical and Isotopic Characteristics of the Water and Suspended Particulate Materials in the Yangtze River and Their Geological and Environmental Implications. Acta Geologica Sinica(English Edition) 88: 276-360.

TOSHIAKI, SAMMORI, YOICHI, OHKURA, HIROTAKA, OCHIAI, HIKARU AND KITAHARA. Effects of Soil Depth on Rain-induced Landslide. Journal of the Japan Society of Erosion Control Engineering 48.

VALLET A, CHARLIER JB, FABBRI 0, BERTRAND C, CARRY N AND MUDRY J. 2016. Functioning and precipitation-displacement modelling of rainfall-induced deep-seated landslides subject to creep deformation. Landslides 13: 653-670.

VAN DH, T. 2014. Experimental dynamic substructuring using direct time-domain deconvolved impulse response functions.

WANG J, XIAO L, ZHANG J AND ZHU Y. 2020. Deformation characteristics and failure mechanisms of a rainfall-induced complex landslide in Wanzhou County, Three Gorges Reservoir, China. Landslides 17: 419-431.

WANG Y, YUE J, DONG Y AND HU Z. 2016. Review on Kernel based Target Tracking for Autonomous Driving. Journal of Information Processing 24: 49-63.

XIN M. 2016. Landslide risk assessment techniques considering the activity state of slopes. Masters, Chengdu University of Technology.

YAN Y, DA-SHEN Y, DONG-XIAN G, SHENG H, ZI-ANG W, WANG H AND SHU-YAO Y. 2019. Disaster reduction stick equipment: A method for monitoring and early warning of pipeline-landslide hazards. Journal of Mountain Science 16: 2687-2700.

YANG L, LU RN, TAN DJ, XIE HB AND LUO ZF. 2012. Study on Interpretation of Landslides Based on Gis - Taking New Fengjie County in Chongqing as an Example. Applied Mechanics and Materials 1975.

YI-TING W, CHRISTOFFEL SA, WILLEM B AND QING-TA0 C. 2015. Using Statistical Learning Algorithms in Regional Landslide Susceptibility Zonation with Limited Landslide Field Data. Journal of Mountain Science 12: 268-288.

YIN Y, HUANG B, WANG W, WEI Y, MA X, MA F AND ZHAO C. 2016. Reservoir-induced landslides and risk control in Three Gorges Project on Yangtze River, China. Journal of Rock Mechanics and Geotechnical Engineering 8: 577-595.

YUAN L. 2005. Research on forecast and early warning methods of regional rainfal1- 

type landslides. PhD, China University of Geosciences (Beijing). YUE-LI C, DE-HUI C, ZE-CHUN L AND JUN-BAO H. 2016. Preliminary studies on the dynamic prediction method of rainfall-triggered landslide. Journal of Mountain Science 13: 1735-1745. ZE-LIN Z, TAO W AND SHU-REN W. 2020. Distribution and features of landslides in the Tianshui Basin, Northwest China. Journal of Mountain Science 17: 686-708. ZHIYUN D, XINRONG L, YONGQUAN L, SHULIN L, YAFENG H, JINHUI L AND YILIANG T. 2020. Model test and numerical simulation on the dynamic stability of the bedding rock slope under frequent microseisms. Earthquake Engineering and Engineering Vibration 19: 919-935.

ZHU QING MS, DING YULIN, QI HUA, HE XIAOBO, CAO ZHENYU. 2017. Knowledge-guided Gross Errors Detection and Elimination Approach of Landslide Monitoring Data. Geomatics and Information Science of Wuhan University: 42(44). 

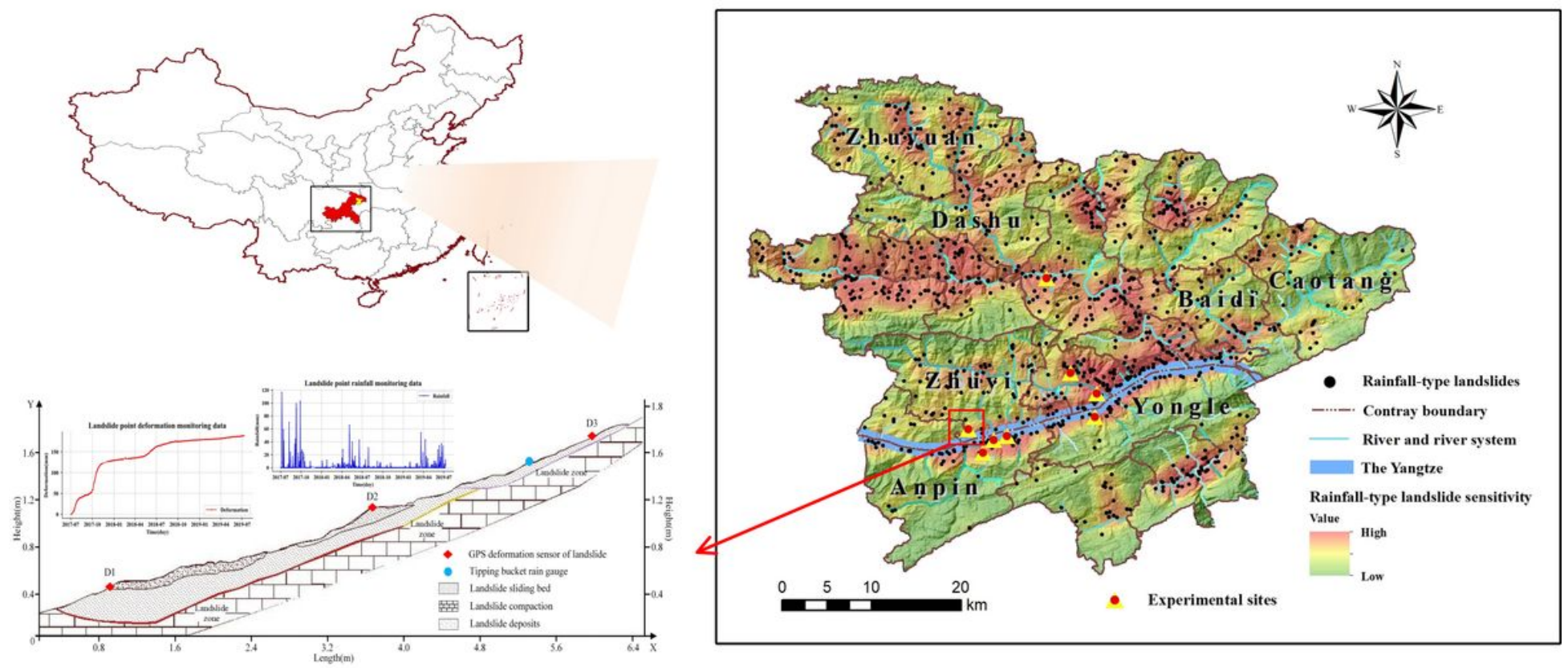

Figure 1

The tests were conducted at rainfall-triggered landslides such as the Xinpu landslide in Fengjie County. Chongqing, China Note: The designations employed and the presentation of the material on this map do not imply the expression of any opinion whatsoever on the part of Research Square concerning the legal status of any country, territory, city or area or of its authorities, or concerning the delimitation of its frontiers or boundaries. This map has been provided by the authors.

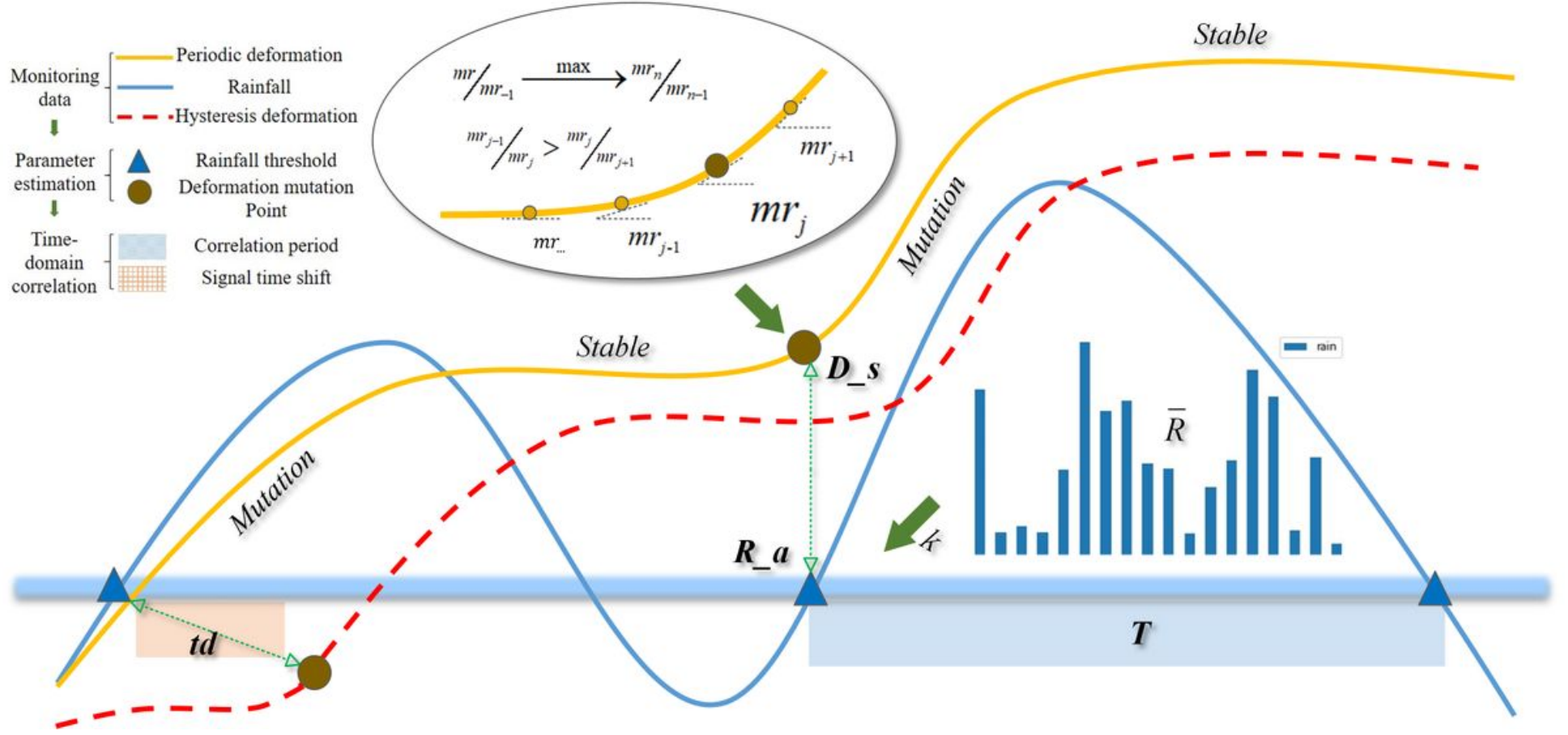

Figure 2 
Conceptual diagram of regional rainfall-landslide deformation time-domain correlation measurement
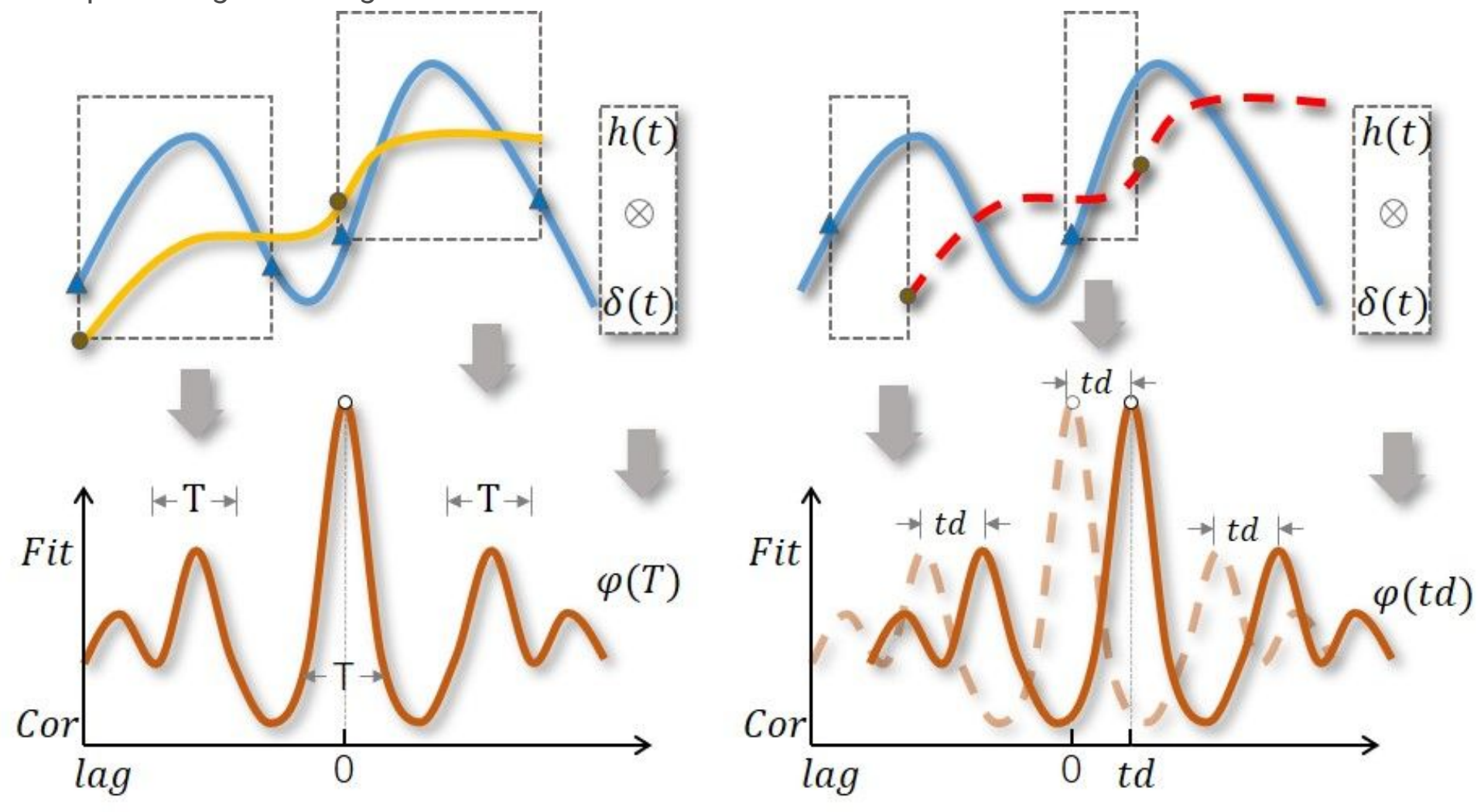

Figure 3

Schematic diagram for calculating time-domain correlation measures based on impulse response functions 


\section{(1)Landslide area monitoring data}

regional rainfall monitoring data

landslide deformation monitoring data

\section{(2)Adaptive Kalman filtering for hierarchical noise reduction}

Time-series data processing $\rightarrow$ Time domain feature extraction $\rightarrow$ Adaptive parameter constraints $\rightarrow$ hierarchical noise reduction

\section{(3)Structural transformation of monitoring signal with correlation measurement constraints}

[Landslide deformation signals] $\quad$ Signal transformation based on time-domain Dis $=\left\{d_{0}, d_{1}, d_{2}, d_{3}, \ldots d_{n}\right\}$

[Regional Rainfall Signals]

Rain $=\left\{r_{0}, r_{1}, r_{2}, r_{3}, \ldots r_{n}\right\}$

[deformation mutation signals]

$V s s=\left\{v_{0}, v_{1}, v_{2}, v_{3}, \ldots v_{n}\right\}$

correlation measures

Dis-\{d $\left\{\begin{array}{c}d_{\tau_{1}} \\ d_{T_{2}}, \ldots \\ \left.d_{T_{n}}\right\}\end{array}\right.$

[Periodic rainfall]

Rain $=\left\{r_{r_{1},}^{\uparrow}, r_{\tau_{2}}, \ldots, r_{T_{n}}\right\}$

[Periodic mutation]

$V s s=\left\{v_{T_{1}}, v_{T_{2}}, \ldots, v_{T_{n}}\right\}$

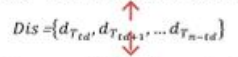

[Time-shifted rainfall]

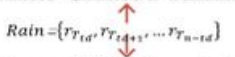

[Time-shifted mutation] | $V s s=\left\{v_{T_{t a d}}, v_{T_{t d t}}, \ldots, v_{T_{n-t}}\right\}$

$-1-1-1$

\section{(4)Quantitative analysis of regional rainfall-landslide deformation response}

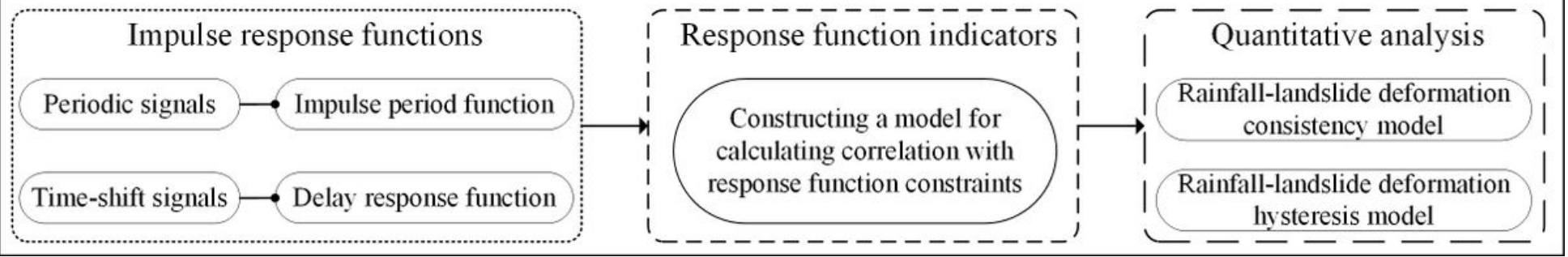

\section{Figure 4}

Flow chart of the regional rainfall-landslide deformation quantitative response analysis algorithm

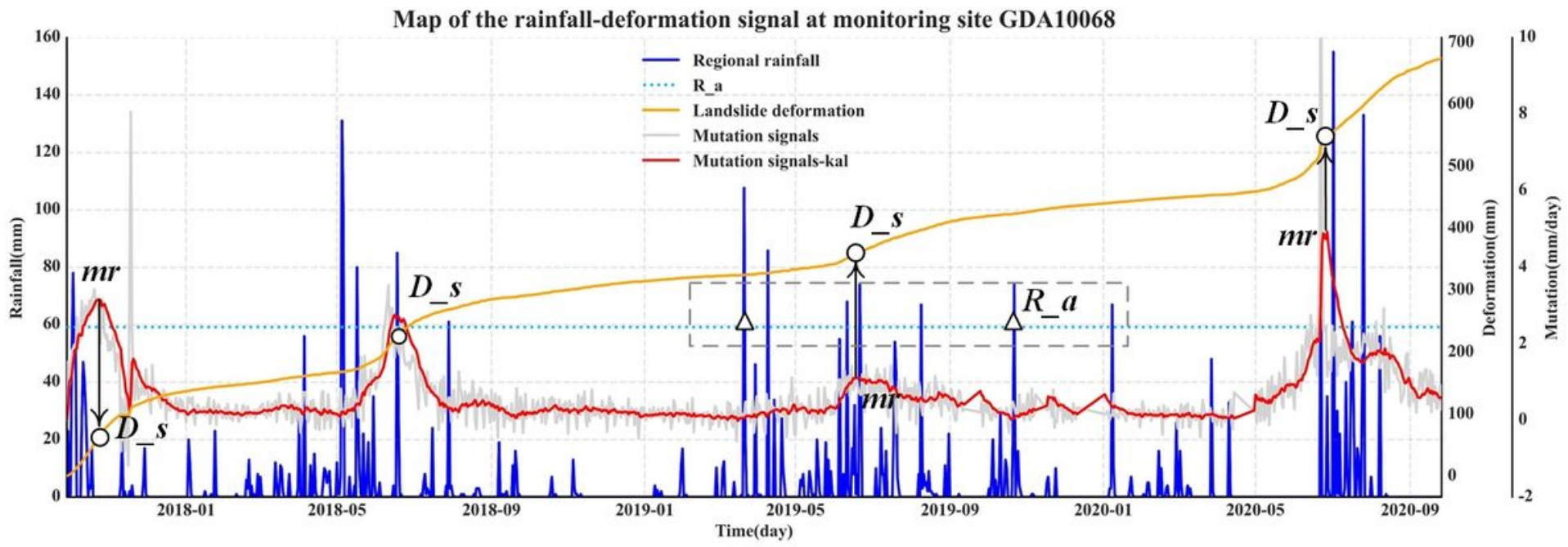


Figure 5

Map of monitoring data at landslide site GDA10068. Used to calculate rainfall-triggered deformation value, mutation signals and the corresponding Kalman filter results

Time-domain correlation measures in clustered monitoring data
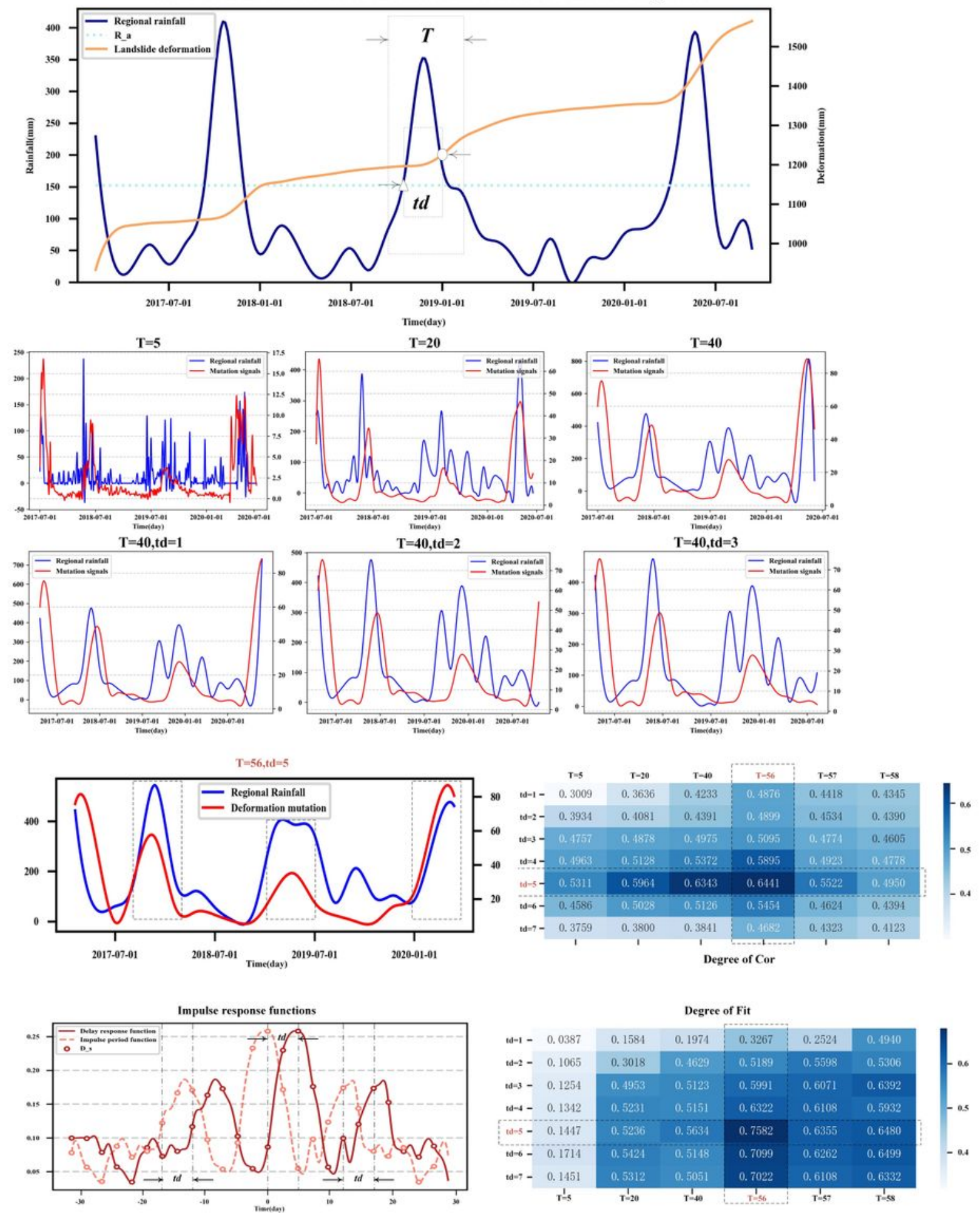

Figure 6 
Map of the results of the test using the time-domain correlation quantitative analysis model at landslide site GDA10068 (a) This figure illustrates the process of monitoring signals for period clustering using the time domain correlation measure described and the signal time shifting. The correlation measure Cor is also measured quantitatively (b) This figure shows the quantitative calculation of the signal after the clustering and time-shifting operations. The value of Cor tells us the optimal T and td (c) Response function construction and quantitative calculation results for correlated signals. The value of Fit tells us the optimal $\mathrm{T}$ and $\mathrm{td}$ 